\title{
Pesantren Hybrid Worldview: Moderatisasi Paradigma Penalaran Keislaman dan Pemenangan Kontestasi Wacana Daring
}

\section{Mochammad Zaka Ardiansyah ${ }^{\text {a) }}$}

a) Program Studi Pendidikan Agama Islam, Fakultas Tarbiyah dan Ilmu Keislaman, IAIN Jember, ORCID iD https://orcid.org/0000-0002-0842-3150

\section{ABSTRAK}

Hingga 2016, Badan Nasional Penanggulangan Terorisme (BNPT) mengungkap bahwa pesantren di Indonesia belum steril dari radikalisme. Di sisi lain, kontestasi wacana di jagat maya menuntut santri dan alumni pesantren untuk menyampaikan pesan damai guna mengimbangi wacana radikal tersebut. Melalui artikel ini, penulis menawarkan hybrid worldview, yakni cara pandang dan revolusi kurikulum pesantren moderat yang mendorong santri melestarikan tradisi kepatuhan mutlak pada kiai. Cara pandang ini juga mendorong santri agar fokus mengembangkan nalar kritis, memiliki kompetensi penalaran paradigmatik yang adaptif terhadap dinamika zaman dan menerima perbedaan, bersikap rasional dan otonom, serta selektif terhadap literatur siswa pesantren. Artikel ini merekomendasikan keahlian coding dengan bahasa pemrograman $\mathrm{R}$ dan pengelolaan big data bagi santri. Hal ini bertujuan untuk mempercepat pertumbuhan produsen portal wacana moderat untuk memenangkan dominasi wacana daring.

\section{ABSTRACT}

Until 2016, National Board for Terrorism Prevention (BNPT) indicates that Indonesian pesantren has not been yet spotless from radicalism. On the other hand, discourse contestation in virtual world requires santri and pesantren alumni to convey peaceful messages in an attempt to balance radical discourses. Through this article, the author offers a hybrid worldview, a perspective and curriculum revolution of moderate that encourages santri to preserve the tradition of obedience to kiai. This perspective also encourages students to focus on developing critical reasoning, to have paradigmatic reasoning competencies that are adaptive to the dynamics of current period and tolerant to differences, to be rational and autonomous, and to be selective towards the literature used by of pesantren students. This article recommends coding skills with the $\mathrm{R}$ language programming and big data management for santri. This aims to accelerate the growth of the moderate internet portal creators in order to dominate online discourse.

\section{KATA KUNCI}

Radikalisme Agama; Pesantren Moderat; Hybrid Worldview; Student-centered Learning; Kontestasi Wacana

\section{KEYWORDS}

Religious Radicalism; Moderate Pesantren; Hybrid Worldview; Student-centered Learning; Discourse Contestation

\section{A. Pendahuluan}

Dalam halaqah yang diselenggarakan penulis bersama tim di Pesantren Miftahul Ulum, Kalisat, Jember di penghujung $2016,{ }^{1}$ penulis dikejutkan oleh paparan paparan $\mathrm{Ra}^{2}$ Itqon. $^{3}$ Salah seorang pengasuh pesantren Pesantren Miftahul Ulum ini menyatakan bahwa Taman Kanak-kanak Nurul Huda,

\footnotetext{
${ }^{1}$ Halaqah ini merupakan rangkaian kegiatan pengabdian berbasis pesantren yang didukung oleh Diktis Kemenag RI.

${ }^{2} R a$ atau Lora adalah penggilan kepada seorang putera Kiai pesantren dalam bahasa Madura.

${ }^{3}$ Ra Itqon menyatakan di hadapan peserta halaqah dan ditujukan secara khusus kepada Pak Widi, Kepala Bakesbangpol Kabupaten Jember yang juga menjadi pemateri halaqah tersebut Transkrip Halaqoh Pesantren Sebagai Pusat Komunitas Anti Radikalisme, amr (Musala Ponpes Miftahul Ulum Taman Baru, 2016); Ra Itqon telah memberikan kesediaan untuk menampilkan nama TK Nurul Huda dalam paper ini Itqon Syauqi, “Wawancara Pernyataan Kesediaan Untuk Dipublikasikan," Desember 2018.

CONTACT Mochammad Zaka Ardiansyah $\square$ zaka.ardiansyah@iain-jember.ac.id $\square$ Jl. Mataram No. 1 Mangli, Jember, Jawa Timur, Indonesia, 68136

(CC BY-NC-SA 4.0) (C2019 Jurnal Pendidikan Agama Islam (Journal of Islamic Education Studies)
} 
sebuah lembaga pendidikan di bawah naungan pesantren Miftahul Ulum, tanpa sengaja menggunakan buku latihan membaca anak yang disinyalir mengandung radikalime. ${ }^{4}$

Jika pesantren Miftahul Ulum dan pesantren-pesantren moderat lain tak melakukan screening buku yang digunakan sekolah dan madrasahnya dengan ketat, maka tak mustahil wajah pesantren moderat seperti Miftahul Ulum akan berubah mengingat internalisasi informasi pada siswa TK di bawah naungan pesantren berimbas pada perubahan wajah pesantren dan alumninya masa depan. Kekhawatiran ini cukup mendasar karena pada awal 2016 BNPT menyatakan bahwa 19 pesantren di Indonesia masuk dalam "zona awas" radikalisme. ${ }^{5}$

Di sekolah umum, wajah suram pendidikan Indonesia masih ditunjukkan dari hasil riset PPIM UIN Jakarta --sebagaimana dirilis oleh Convey Indonesia-- yang menyatakan bahwa 62,22 persen guru menyetujui syariat Islam sebagai dasar pemerintahan terbaik. Riset ini menyimpulkan bahwa 37.77 persen guru intoleran dan 41,26 persen lainnya radikal, dan guru TK dan RA memiliki opini lebih intoleran daripada jenjang di atasnya. ${ }^{6}$

Guru mata pelajaran umum dan guru agama/guru PAI yang intoleran ${ }^{7}$ menjadi momok dunia pendidikan, khususnya sekolah umum, mengingat diversitas sosio kultur-religius di sekolah umum merupakan realitas yang tidak terelakkan. ${ }^{8}$ Realitas ini seperti gayung bersambut dengan wajah pemikiran siswa SMA dan mahasiswa yang dibaca dengan literatur keislamannya, karena berdasar riset PPs UIN Sunan Kalijaga pada 2018 diketahui Muslim milenial banyak mengonsumsi buku-buku islamisme, variannya pertama literatur keislaman ideologis, yakni tahriri, tarbawi dan jihadi, kedua, literatur puritan, yakni literatur yang dibuat oleh kelompok salafi yang berisi teks bersanad tokohnya untuk melegitimasi

\footnotetext{
${ }^{4}$ Radikalisme dalam pandangan Hasan Baharun dipandang sebagai doktrin tekstual dalam Islam yang cenderung mendorong penganutnya untuk terlibat dengan Islamisme. Tujuan utama dari doktrin ini adalah gerakan untuk kepentingan ekonomi dan politik. Lihat Hasan Baharun dan Robiatul Awwaliyah, "Pendidikan Multikultural dalam Menanggulangi Narasi Islamisme di Indonesia", Jurnal Pendidikan Agama Islam (Journal of Islamic Education Studies), Vol. 5, No. 2 (2017). Bandingkan dengan Masdar Hilmy, "Radikalisme Agama dan Politik Demokrasi di Indonesia Pasca-Orde Baru", Miqot: Jurnal Ilmu-ilmu Keislaman, Vol. 39, No. 2 (2015).

${ }^{5}$ Republika, "BNPT Curigai 19 Pondok Pesantren Dukung Terorisme," Republika Online, last modified February 2, 2016, accessed September 10, 2016, http://www.republika.co.id/berita/nasional/umum/16/02/02/o1xafr365-bnpt-curigai-19-pondokpesantren-dukung-terorisme.

${ }^{6}$ Survei Nasional Tentang Sikap Keberagamaan Guru Sekolah/Madrasah di Indonesia Convey Indonesia, "Survei PPIM 2018: Ada 3 Hal Terkait Intoleransi Dan Radikalisme Di Kalangan Guru - Convey Indonesia," n.d., accessed December 6, 2018, https://conveyindonesia.com/survei-ppim-2018-ada-3-hal-terkait-intoleransi-dan-radikalisme-di-kalangan-guru/ Bandingkan dengan; PPIM, "Survei PPIM 2018: Menyibak Intoleransi Dan Radikalisme Guru," PPIM / Pusat Pengkajian Islam Dan Masyarakat, accessed December 6, 2018, https://ppim.uinjkt.ac.id/category/2/post/survei-ppim-2018:-menyibak-intoleransi-dan-radikalismeguru.

${ }^{7}$ Istilah intoleran ini mengandung makna bahwa guru yang tidak memahami aspek kebudayaan Islam di Indonesia, sehingga mereka cenderung memaksakan dan mengintimidasi corak keislaman murni menurut paradigma kelompok radikal. Ditambah lagi, kerangka berfikir guru disublimasi dalam bentuk budaya keislaman yang kuat, melalui organisasi siswa, dan kegiatan ekstra kulikuler di luar sekolah. Lihat S. Mahmudah Noorhayati, "Redesain Paradigma Pendidikan Islam Toleran dan Pluralis di Pondok Pesantren (Studi Konstruktivisme Sikap Kiai dan Sistem Nilai di Pondok Pesantren Nurul Jadid, Paiton, Probolinggo)", Jurnal Pendidikan Agama Islam (Journal of Islamic Education Studies), Vol. 5, No. 1 (2017).

8 PPIM, "Survei PPIM 2018: Menyibak Intoleransi Dan Radikalisme Guru."
} 
purifikasi dan ketiga literatur kesalehan populer yang terdiri dari buku-buku self-help, islamisme populer dan motivasi. ${ }^{9}$

Lembaga pendidikan masyarakat, baik madrasah diniyah, sekolah, madrasah reguler, pesantren dan masjid pemerintah di atas negara bineka --yang alih-alih mengedukasi siswa dan masyarakat untuk saling menghargai sebagai manifestasi dari sila ketiga Pancasila-- justru kecolongan karena dimanfaatkan oleh kelompok keagamaan intoleran-tekstual-puritan yang memiliki struktur kognitif yang tak ramah pada diversitas dan/atau agenda yang tidak menguntungkan masa depan persatuan negara-bangsa ini.

Salah satu produk lembaga pendidikan yang masih dapat diharapkan menjadi benteng pertahanan kesatuan bangsa adalah pesantren moderat, ${ }^{10}$ lembaga pendidikan yang telah menghasilkan banyak alumni yang loyal terhadap NKRI. Namun di sisi lain, menurut catatan Lukens-Bull, lembaga pendidikan Islam di berbagai negara kerap dicitrakan oleh media dan pembuat kebijakan di Barat biang kerok radikalisme. ${ }^{11}$ Stigma ini berdasarkan analisis Moulton muncul karena beberapa pelaku teror atas nama agama terindikasi alumni dari madrasah-madrasah di perbatasan Afganistan dan Pakistan, sehingga stigma bahwa lembaga pendidikan Islam di kawasan tersebut mentransmisikan fanatisme keagamaan dan anti modernitas tak terelakkan. ${ }^{12}$

Klaim yang kedua ini tidak mengejutkan, meskipun tidak dapat digeneralisir dalam lanskap Indonesia, mengingat Indonesia memiliki pekerjaan rumah untuk melokalisir sebaran radikalisme di 19 pesantren yang terindikasi radikal meski secara kuantitatif kontras dengan jumlah keseluruhan 25.938 pesantren di Indonesia. ${ }^{13}$ Meskipun demikian, bagi penulis, temuan ini merupakan alarm yang mengindikasikan tidak sterilnya pesantren di Indonesia dari radikalisme karena tampak menunjuk hidung pesantren sebagai lembaga pendidikan sacred yang menampilkan wajah profan yang tak sejalan dengan misi kemanusiaan.

Keterkaitan lembaga pendidikan Islam dengan radikalisme sebagaimana paparan Moulton kontras dengan temuan dan analisis Lukens-Bull di Indonesia. Pesantren, sebagai lembaga pendidikan Islam tradisional di Indonesia menurutnya justru menjadi lembaga pendidikan keagamaan yang menghasilkan alumni anti-radikalisme dan berkontribusi dalam perdamaian dunia. Di antara alasannya karena pesantren mengajarkan kesalehan sosial, diantaranya dengan mistisisme sufistik. ${ }^{14}$ Argumen

\footnotetext{
${ }^{9}$ Munirul Ikhwan, “Produksi Wacana Islam(Is) Di Indonesia: Revitalisasi Islam Publik Dan Politik Muslim,” in Literatur Keislaman Generasi Milenial: Transmisi, Apropriasi, Dan Kontestasi, ed. Noorhaidi Hasan (Yogyakarta: Pascasarjana UIN Sunan Kalijaga Press, 2018), 74-98.

${ }^{10}$ Istilah moderat merupakan resapan dari kata seimbang tidak terlalu ke kanan (ifrat) dan tidak terlalu ke kiri (tafrit), di dalamnya terkandung makna keadilan, keistiqomahan, kebaikan, keamanan dan kekuatan. Dalam hal pesantren, karakter moderat dapat diindikasikan dengan sikap toleransi, adanya pemaduan antara akal dan wahyu, dan menyeimbangkan antara bermadzhab secara qouli (memutus persoalan dengan menggunakan teks figh) dan bermadzhab secara manhajii (memutus persoalan dengan kaidah fiqh dan ushul fiqh). Lihat Asror Baisuki, "Penanaman Karakter Moderat di Ma'had Aly Situbondo", Edukasi: Jurnal Penelitian Pendidikan Agama dan Keagamaan, Vol. 15 No. 3 (Desember 2017).

${ }^{11}$ Ronald Lukens-Bull, "The Tradition of Pluralism, Accomodation, and Anti Radicalism in the Pesantren Community," Journal of Indonesian Islam 2, no. 1 (June 2008): 1.

12 Jeanne Moulton, Madrasah Education: What Creative Associates Has Learned (Washington DC: Creative Associates International, 2008), 3.

13 "Pangkalan Data Pondok Pesantren," accessed December 7, 2018, http://pbsb.ditpdpontren.kemenag.go.id/pdpp/grafik.

${ }^{14}$ Lukens-Bull, "The Tradition of Pluralism, Accomodation, and Anti Radicalism in the Pesantren Community," 2.
} 
Mochammad Zaka Ardiansyah

Lukens-Bull menyerupai paparan Masduqi yang sepakat bahwa pesantren berkontribusi pada deradikalisasi karena dalam proses pembelajarannya mengajarkan kerukunan, kesantunan dan humanisme..$^{15}$

Namun berbeda dengan pandangan di atas, penulis dalam berdasarkan data yang terungkap dalam forum halaqah yang melibatkan pengelola pesantren dan alumninya --yang diselenggarakan penulis dan tim di sebuah pesantren moderat di Jember Utara pada penghujung 2016 sebagai bagian dari pengabdian berbasis pesantren-- menemukan fakta bahwa TK di bawah holding pesantren moderat sekalipun, masih dapat kecolongan memanfaatkan buku latihan membaca yang mengandung kata radikal. ${ }^{16}$

Setidaknya faktor yang berkontribusi pada dinamika pesantren adalah globalisasi dan modernisasi, ${ }^{17}$ kemudahan akses informasi, ${ }^{18}$ meningkatnya global salafism, ${ }^{19}$ radikalisme, ${ }^{20}$ realitas global village, ${ }^{21}$ khususnya dampak revolusi industri 4.0. Literasi keagamaan dan pola rekrutmen pengajar lembaga pendidikan Islam di bawah holding institution-nya ${ }^{22}$ turut mendorong warna pesantren semakin variatif, sehingga wajah pesantren kini makin variatif seiring dengan beragamnya varian ideologi kiai dan pengasuh pesantrennya, ${ }^{23}$ tak lagi sewarna sebagaimana analisis Lukens-Bull sepuluh tahun silam. Realitas wajah pesantren hari ini pun juga tidak lagi relevan dengan analisis Geertz yang menyatakan bahwa pesantren melahirkan manusia yang memiliki etika dan etos kerja yang tinggi, khususnya untuk bekerja di sektor non-formal meski hobi berdoa di kuburan, mengalokasikan banyak waktunya untuk berzikir dan selawat. ${ }^{24}$

Sebagai lembaga pendidikan yang tumbuh dari masyarakat, pesantren telah turut berperan menyelenggarakan proses pendidikan yang telah mentransmisikan ilmu holistik, ${ }^{25}$ sehingga jika tradisi

${ }^{15}$ Irwan Masduqi, “Deradikalisasi Pendidikan Islam Berbasis Khazanah Pesantren," Jurnal Pendidikan Islam 2, no. 1 (June 2013): 120.

${ }^{16}$ Transkrip Halaqoh Pesantren Sebagai Pusat Komunitas Anti Radikalisme.

${ }^{17}$ Dalam paper ini Lukens-Bull meneliti strategi pesantren mengantisipasi globalisasi dan modernisasi, meskipun paper ini merupakan hasil etnografinya hampir dua dasawarsa lalu, namun menunjukkan bahwa sejak saat itu pesantren, dalam hal ini diwakili oleh pesantren Tebuireng telah melakukan sejumlah strategi untuk menghadapinya. Roland A. Lukens-Bull, "Teaching Morality: Javanese Islamic Education in A Globalizing Era," Journal of Arabic and Islamic Studies 3 (2000): 28.

${ }^{18}$ Hoda Baytiyeh, "Have Globalisation's Influences on Education Contributed to The Recent Rise of Islamic Extremism?," Globalisation., Societies and Education (2018): 3.

${ }^{19}$ Noorhaidi Hasan, "The Failure of the Wahhabi Campaign Transnational Islam and the Salafi Madrasa in Post-9/11 Indonesia," South East Asia Research 18, no. 4 (n.d.): 676.

${ }^{20}$ Moulton, Madrasah Education: What Creative Associates Has Learned, 3.

${ }^{21}$ McLuhans telah memprediksi bahwa otomasi akan membuat batas lingkungan menjadi tak terbatas, sehingga luasan "lingkungan" menjadi tak terbatas. Marshall McLuhan and Quentin Fiore, War and Peace in the Global Village (New York: Bantam Books, 1968), 11.

${ }^{22}$ Azyumardi Azra and Dina Afrianty, "Pesantren and Madrasa: Modernization of Indonesian Muslim Society" (presented at the Workshop in Madrasa, Modernity and Islamic Education, Boston: Boston University, 2005).

${ }^{23}$ Umma Farida, "Radikalisme, Moderatisme Dan Liberalisme Pesantren: Melacak Pemikiran Dan Gerakan Keagamaan Pesantren Di Era Globalisasi," Edukasia 10, no. 1 (2015): 145-162.

${ }^{24}$ Dhofier menilai analisis Geertz tidak konsisten, karena di satu sisi ia mengklasifikasikan orang pesantren sebagai "the conservative muslim" yang masuk dalam kriteria santri, namun di sisi lain diidentifikasi sebagai manusia sinkretis yang relevan dengan ciri abangan yang relevan dengan kriteria abangan Geertz. Zamakhsyari Dhofier, "The Pesantren Tradition: A Study of the Role of the Kyai in the Maintenance of the Traditional Ideology of Islam in Java" (Disertasi, Australia National University, 1980), xii-xvi.

${ }^{25}$ Said Aqil Siradj, Tasawuf Sebagai Kritik Sosial: Mengedepankan Islam Sebagai Inspirasi Bukan Aspirasi (Bandung: Mizan, 2006), 224 
pendidikan ini dijaga, maka tidak mungkin pesantren mampu menghasilkan ilmuwan Muslim yang memiliki competent worldview ${ }^{26}$-punya kompetensi 'ulüm al din sekaligus menguasai keilmuan sekulerdan beriman dan bertakwa ${ }^{27}$ sehingga analisis masalah sosial serta produk hukum Islam yang dihasilkannya dapat komprehensif, berkaca pada konsensus keislaman sekaligus perkembangan terkini ilmu pengetahuan.

Berdasarkan kegelisahan akademik di atas, artikel ini berusaha memberikan pemikiran pengembangan pesantren moderat Miftahul Ulum, Kalisat, Jember melalui hybrid worldview pada para siswanya, yakni cara pandang dan pengembangan kurikulum pesantren dan lembaga holdingnya agar dapat dapat mempertahankan kepatuhan mutlak pada kiai namun mengembangkan pembelajaran kritis sambil mengembangkan nalar kritis, memiliki cara pandang komprehensif, adaptif, menghargai perbedaan rasional dan otonom, melakukan screening literatur bermuatan radikal dan serius mengembangkan coding dan big data skills sebagai basic digital skill. Keterampilan terakhir sangat penting untuk turut turun ke medan pertarungan wacana moderat melawan dan mengimbangi narasi radikal yang ditransmisikan kelompok radikal melalui media daring.

\section{B. Pesantren Miftahul Ulum: Kiai Bandongan, Kiai Panggung dan Kiai Blusukan}

Sebagaimana pesantren lain di kawasan Jember Utara, pesantren Miftahul Ulum juga memiliki lembaga pendidikan formal PAUD, TK, MI, MTs dan MA yang menyelenggarakan pendidikan keagamaan dan umum, serta madrasah diniyah. Terletak di pinggiran episentrum kawasan sub-urban Kalisat, Jember membuat pesantren ini sepi dalam keramaian yang menjadi gangguan belajar bagi santri dan siswa pesantren. Pesantren ini terbagi menjadi dua asrama dan beberapa pengajian bandongan yang diasuh oleh kiai Rosyidi Baihaqi, di sisi Selatan berdiri asrama pesantren Miftahul Ulum yang terletak di kawasan Tamanan yang memiliki beragam unit pendidikan formal dan non-formal yang berdiri kokoh dengan mayoritas bangunan bertembok.

Sementara di 50 meter di Utaranya, di kawasan Taman Baru, berdiri pesantren Miftahul Ulum yang diasuh oleh Kiai Sanusi yang fokus pada pembelajaran pesantren salaf dengan beberapa bangunan pemondokan yang bertembok dan sebagian masih berbahan kayu. Para santri di kedua asrama juga mengikuti pengajian yang diselenggarakan kiai Solehuddin di rumahnya secara bandongan.

Miftahul Ulum sebagai holding institution dipimpin oleh ketua yayasan Kiai Rosyidi Baihaqi sekaligus pengasuh asrama pesantren di kawasan Tamanan. Pengalamannya sebagai seorang mantan dosen Universitas Jember sekaligus pemilik KBIH membuatnya semakin luwes berkomunikasi dengan masyarakat sebagai "kiai panggung". Tak hanya ceramah di kawasan yang dipimpin para alumninya,

\footnotetext{
${ }^{26}$ Seorang ahli hukum Islam yang tidak memiliki competent worldview, yakni disamping penguasaan ilmu keislaman juga penguasaan sains yang baik tidak akan menghasilkan produk hukum yang akurat dan berpotensi bias dengan hasil riset kontemporer yang terkait dengan produk hukum tersebut. Jasser Auda, Maqasid al-Syari'ah as Philosophy of Islamic Law: A Systems Approach (London: The International Institute of Islamic Thought, 2007), 204.

${ }^{27}$ Siradj, Tasawuf Sebagai Kritik Sosial: Mengedepankan Islam Sebagai Inspirasi Bukan Aspirasi, 224.
} 
Mochammad Zaka Ardiansyah

namun retorika yang tertata baik membuat kiai ini populer hingga banyak memiliki jadwal rutin dan undangan ceramah di kawasan Tapal Kuda.

Pesantren yang pengajiannya menggunakan bahasa Madura inipun cukup unik karena memiliki kiai Solehuddin, kiai yang tak hanya mengasuh pengajian bandongan sebagaimana kiai Sanusi --pengasuh pesantren Miftahul Ulum di Taman Baru yang berjarak 100 meter dari pesantren utama--, namun juga memiliki kebiasaannya mengunjungi rumah alumni-alumninya dan masyarakat hingga larut malam, ${ }^{28}$ kebiasaan blusukan ini dilakukan hampir setiap malam sehingga banyak alumni, khususnya di kawasan Jember dan sekitarnya sangat takzim pada beliau.

Sebagai pesantren yang bertradisi $N U,{ }^{29}$ pesantren moderat ini memasukkan materi Aswaja sebagai mata pelajaran di madrasah formal di samping ke-NU-an dan mempelajarinya di kelas madrasah diniyah kelas 2 'Ula dan kelas 3 Wustha. Sebagaimana pembelajaran di madrasah lain, materi di madrasah formal dan madrasah diniyah belum dilaksanakan dengan active learning dan masih berpusat pada guru (Student-Centered Learning). ${ }^{30}$

Pesantren ini memiliki SDM muda yang bertalenta di bidang kepenulisan wacana, beberapa putra kiai dan famili pesantren merupakan alumni UGM dan memiliki tradisi menulis yang baik, sebut saja Ra Ahmad Badrus Solihin dan Ra Itqon Syauqi.

\section{Literatur Radikal di Lembaga Pesantren}

Meski pesantren Miftahul Ulum memiliki SDM yang cukup mumpuni dalam mengembangkan literasi dan tradisi moderat, namun buku berkonten radikal dapat beredar dalam literatur lembaga pendidikan di bawah naungannya. Buku yang dimaksud adalah buku latihan membaca berjudul Anak Islam Suka Membaca. Buku ini mengandung lebih dari 20 kata dan kalimat yang mengarah pada ajakan melakukan tindak kekerasan dan pengenalan instrumen perang --seperti "selesai raih bantai kiai", "rela mati bela agama", "bazoka dibawa lari". 31

Internalisasi kata-kata radikal pada siswa yang dilakukan tanpa sengaja oleh guru TK dapat berkontribusi dalam konstruksi skema siswa terhadap konsep baru tersebut. ${ }^{32}$ Endapan keywords radikal

\footnotetext{
${ }^{28}$ Badrus, "Wawancara Profil Pesantren Miftahul Ulum Kalisat Jember," March 10, 2016.

${ }^{29}$ Sebagaimana kita ketahui Nahdlatul Ulama (NU) yang sedari lahirnya memproklamirkan diri sebagai organisasi pelestari tradisi dan nilai-nilai luhur budaya bangsa. Dengan menjadikan ahlu al sunnah wa al jama'ah sebagai basis telologis, NU mempopulerkan jargon 'Al-Muha>faz\}atu 'ala> al-qadi>m al-sha>lih wa al-akhdhu bi al-jadi>d al-as\}lah\}' (memelihara tradisi yang baik dan mengambil hal baru yang lebih baik). Jargon tersebut kemudian diterjemahkan oleh Gus Dur dengan istilah pribumisasi Islam; sebuah gagasan yang memiliki beberapa karakteristik, di antaranya: pertama, Islam tidak dianggap sebagai alternatif ideologi, melainkan hanya dipandang sebagai faktor komplementer saja dalam kehidupan sosial, kultural, dan politik. Kedua, toleran dan menghargai tradisi, yaitu perlunya mempertimbangkan konteks lokal Indonesia ketika menerapkan ajaran Islam. Ketiga, progresif, bahwa Islam harus bisa berlapang dada untuk berdialog dengan tradisi pemikiran orang lain, termasuk dengn Barat. Keempat adalah membebaskan, Islam menjadi ajaran yang dapat menjawab problem kemanusiaan secara universal tanpa melihat perbedaan etnik maupun agama. Lihat Zakiya Darajat, "Muhammadiyah dan NU; Penjaga Moderatisme Islam di Indonesia", Hayula: Indonesian Journal of Multidisciplinary Islamic Studies, Vol. 1, No. 1 (Januari 2017).

${ }^{30}$ Badrus, “Wawancara Tradisi Belajar di Sekolah Dan Madrasah Pesantren Miftahul Ulum Kalisat Jember," Desember 2018.

${ }^{31}$ Kata-kata tersebut terdapat menyebar pada jilid 1-5 buku Anak Islam Suka Membaca cetakan ke 167 karya Nurani Musta'in yang terbit November 2013.

32 John W. Santrock, Child Development: An Introduction, Thirteenth Edition. (New York: McGraw-Hill, 2011), 209.
} 
ini --Slavin menyebutnya dengan existing schemes-- pada gilirannya di masa depan dapat dipanggil kembali oleh siswa untuk digunakan dalam memahami informasi baru melalui proses asimilasi, yakni proses kognitif di mana informasi baru yang diperoleh anak relevan, memperkaya dan mengukuhkan skema yang telah dimiliki. ${ }^{33}$

Melalui asimilasi, para siswa yang semasa di TK ini tanpa sengaja melakukan akuisisi kata kunci radikal melalui buku latihan membaca, jika di sekolah menengah mereka bertemu komunitas, literasi dan guru yang menyajikan kembali kata-kata kunci radikal tersebut, maka mereka akan semakin meyakini kebenaran keywords radikal yang di dapat dari buku membaca TK di atas. Merekapun berpotensi menggunakan skema tersebut untuk mendalami konsep radikalisme yang lebih kompleks. ${ }^{34}$

Mengingat dalam buku tersebut setiap guru TK yang mengajar membaca dengan buku ini diminta untuk menjelaskan arti setiap kata baru, maka skema siswa atas kata tersebut sangat tergantung dari konstruksi makna kata yang diberikan guru sebagai pemegang otoritas informasi dan pemegang kuasa pengetahuan.

Skema awal dan skema yang telah diperkuat melalui asimilasi dapat dinetralisir jika terdeteksi sejak dini. Kontra interpretasi dan kontra narasi atas skema siswa terhadap kata kunci radikal dapat dilakukan melalui internalisasi makna baru atas kata tersebut atau pemberian kontra narasi atas rangkaian kata tersebut sehingga diharapkan siswa mengalami proses kognitif akomodasi, yakni menyesuaikan skema dengan makna baru, pengalaman baru ${ }^{35}$ dan/atau narasi baru. Proses kognitif ini bagian dari upaya deradikalisasi pada siswa yang tanpa sengaja menjadi korban internalisasi kata kunci radikal melalui buku membaca TK.

\section{Educative Tradition: Nalar Kritis dalam Merawat Moderasi Islam}

Dalam konteks kekinian, guna mengukuhkan lembaga pendidikan Islam untuk menyajikan wajah teduh, Tan memberikan kontribusi pemikiran dengan memperkenalkan educative tradition, ${ }^{36}$ yakni konsep yang menurutnya merupakan solusi kebuntuan pemikiran keagamaan dan fanatisme oknum lembaga pendidikan Islam yang mendorong siswanya tidak hanya menerima kebenaran dengan taklid, bersikap anti-totalistic, ${ }^{37}$ dengan wawasan terbuka terhadap perbedaan --untuk tidak mengatakan pluralis ${ }^{38--}$, rasional dan otonom. ${ }^{39}$

Melihat konsep pendidikannya, educative tradition memberikan porsi lebih pada pesantren untuk melatih keterampilan berpikir terbuka dan kritis pada setiap santrinya, meski demikian, jika tidak

\footnotetext{
${ }^{33}$ Robert E. Slavin, Educational Psychology: Theory and Practice, 8th ed. (Boston: Pearson Education, 2006), 32.

${ }^{34}$ Ibid.

${ }^{35}$ John W. Santrock, Educational Psychology, 6th ed. (New York: McGraw-Hill, 2011), 40.

${ }^{36}$ Tan menyebutnya dengan Islamic school with a smilling face Charlene Tan, Islamic Education and Indoctrination: The Case in Indonesia (New York: Routledge, 2011), 91.

${ }^{37}$ Ibid., 79.

${ }^{38}$ Pluralisme dipahami Tan sebagai tindakan mengapresiasi dan membangun hubungan aktif dengan orang dari tradisi berbeda. Ibid., 78.

${ }^{39}$ Charlene Tan, "Educative Tradition and Islamic School in Indonesia," Journal of Arabic and Islamic Studies, no. 14 (2014): 47-48; Bandingkan dengan Tan, Islamic Education and Indoctrination: The Case in Indonesia, 91.
} 
Mochammad Zaka Ardiansyah

diimplementasikan dengan tepat dapat berpotensi menggeser tradisi belajar di pesantren tradisional yang mengedepankan konsep kepatuhan mutlak pada kiai, takzim, hormat ${ }^{40}$ serta berkah. Sebagai holding institution yang mengelola beragam unit pendidikan dan usaha, pesantren moderat sangat mungkin mengintegrasikan beberapa komponen educative tradition yang relevan dengan karakternya dalam kurikulum unit-unit pendidikannya, sementara parameter lain yang tidak relevan nampaknya harus ditanggalkan.

Menjaga tradisi kepatuhan total, hormat dan takzim pada kiai sebagaimana menjadi khas pesantren harus dipertahankan dengan tanpa dicampuri dengan semangat mendorong pembelajaran kritis dan terbuka pada santri. Desain pembelajaran kritis dan terbuka diadopsi dalam pembelajaran madrasah dan sekolah, bukan pada pengajian dengan metode bandongan yang diasuh kiai.

\section{E. Santri, Otomasi, dan Kontestasi Wacana Daring Moderat}

Berdasarkan data yang dirilis McKinsey, pekerjaan yang terkait rutinitas, aktivitas terprediksi, dan pekerjaan yang berhubungan dengan pengumpulan dan pemrosesan data akan tergantikan oleh robot. ${ }^{41}$ McKinsey memprediksi 49 persen pekerjaan manusia akan terotomasi (automated). Perkembangannya hingga kini, 5 persen dari keseluruhan pekerjaan manusia telah diganti oleh robot, sementara 60 persen lainnya 30 persen aktivitasnya akan terotomasi. ${ }^{42}$ Pekerjaan yang paling banyak terancam adalah pekerjaan di sektor akomodasi dan food service sebanyak 73\%, diikuti manufacturing sebanyak $60 \%$ akan tergantikan oleh robot. Di kedua sektor ini, jenis pekerjaan predictable physical yang paling banyak terimbas. $^{43}$

Di sektor informasi, 36\% pekerjaan manusia diprediksi McKinsey terotomasi oleh robot. Di sisi lain, santri dan alumni pesantren dituntut berperan aktif menguasai narasi moderat di media daring, sehingga penting untuk mempersiapkan santri agar dapat memproduksi produk kecerdasan buatan untuk mendiseminasikan gagasan moderat di media daring sebagai konter narasi radikal, caranya dengan mendorong santri menjadi programmer dan memiliki big data skills sehingga santri dapat berdikari menciptakan perangkat lunak untuk yang dibutuhkan untuk melakukan misi perawatan moderatisme ini, karena keahlian coding dapat membuat setiap orang mengubah keadaan dan membuat loncatan inovasi yang tidak dapat dilakukan orang yang gagap coding.

Indonesia berada di peringkat terakhir dari 25 negara dalam kesiapannya menghadapi otomasi, ${ }^{44}$ yakni pengambilalihan kerja statis dan terprediksi manusia oleh robot dan kecerdasan berbasis Artificial Intelligence $(\mathrm{Al})$. Posisi ini kontras dengan Korea Selatan yang telah menyiapkan penduduknya

\footnotetext{
40 Martin van Bruinessen, "Pesantren Dan Kitab Kuning: Pemeliharaan Dan Kesinambungan Tradisi Pesantren," Jurnal Ulumul Qur'an 3, no. 4 (1992): 74.

41 James Manyka et al., A Future That Works: Automation. Employment, and Productivity (McKinsey Global Institute, 2017$)$, 7.

42 Ibid., 5.

43 lbid., 7.

44 The Ecomonist, "The Automation Readiness Index 2018," accessed December 6, 2018, http://automationreadiness.eiu.com.
} 
menghadapi otomasi dengan mengupgrade kurikulumnya dengan memperkuat soft skills dan mengajarkan bahasa pemrograman sebagai basic digital skill sejak sekolah dasar. ${ }^{45}$

Indonesia belum memiliki pengarusutamaan keahlian coding dalam kurikulum pendidikannya ${ }^{46}$ sehingga hingga kini belum menyiapkan generasinya mandiri merespons era otomasi sebagaimana kegelisahan Saadia Zaidi, ${ }^{47}$ namun penguasaan sektor informasi yang terotomasi menjadi domain yang harus dikuasai santri karena menurut hemat penulis "kaum sarungan" telah teruji kerap teruji menjadi satu-satunya pemain yang tampil menghadang radikalisme. Begitupun dalam peran mengendalikan wacana Islam moderat di jagat daring, santri harus tampil terdepan dengan penguasaan coding mengingat loyalitasnya tak terbantahkan dalam pengendalian radikalisme.

Jika dahulu konten berisi wacana moderat diciptakan secara manual dengan "tarian tangan jari di atas keyboard", maka kini datanya dikumpulkan, diriset, dinarasikan dan disajikan secara otomatis dengan teknologi Machine Learning (ML) dan Natural Language Processing (NLP), tentu saja mereka dilatih untuk terus berinovasi.

Di Indonesia portal berita dengan kecerdasan buatan ditabuh oleh beritagar.id. Media daring yang digawangi oleh Jim Geovedi, pakar keamanan siber ini merupakan media daring yang kontennya diproduksi secara otomatis, tanpa menerjunkan jurnalis. Konten berita diperoleh dengan pertama menambang data/data mining informasi terbuka di internet yang berasal dari berita yang diturunkan oleh situs berita daring, dan reportase serta percakapan warganet di media sosial. Kedua, mengolahnya menjadi konten berita secara otomatis. Ketiga, verifikasi manual dengan sumber berita daring jika diperlukan. ${ }^{48}$

Di sisi lain, masih terjadi disparitas kebutuhan skill para data scientist yang dibutuhkan industri dengan kemampuan lembaga pendidikan dalam menyediakan skill alumninya. Berdasarkan riset Mikalef, dkk., ${ }^{49}$ data scientist yang memiliki keterampilan big data skills masih sangat dibutuhkan di masa depan, termasuk sektor informasi dan pendidikan diketahui bahwa menurut pengguna, kebutuhan pasar terhadap keterampilan big data analysis menunjukkan skor 4.08, sementara kemampuan institusi pendidikan hanya menyediakan SDM dengan skill 3,07. ${ }^{50}$

\footnotetext{
${ }^{45}$ The Ecomonist, The Automation Readiness Index: Who Is Ready for The Coming Wave of Automation? (London: The Economist Intelligence Unit, 2018), 15-16.

${ }^{46}$ Pada riset ini, penilaian school autonomy for curriculum design hanya bernilai 0 The Ecomonist, Automation Readiness Index: 2017, n.d., http://www.automationreadiness.eiu.com/static/download/Report.xlsm.

${ }^{47}$ Ecomonist, The Automation Readiness Index: Who Is Ready for The Coming Wave of Automation?, 15.

${ }^{48}$ Beritagar.id merupakan portal berita yang memanfaatkan Machine Learning (ML) dan Natural Language Processing (NLP) untuk mengagregasi konten informasi daring open access, konten hasil sedotan dari media daring mainstream kemudian disunting secara otomatis, diverifikasi jika diperlukan dan menceritakan kembali dengan bantuan mesin. Keterlibatan manusia hanya pada proses verifikasi data jika diperlukan. Beritagar ditunjang oleh Lokadata sebagai porta penyedot, pengolah dan penyaji data dan Rekanalar untuk merekomendasikan konten dan iklan yang relevan dengan konten berita. Beritagar.id, "Tentang Kami - Merawat Indonesia," accessed November 27, 2018, https://beritagar.id/tentang-kami.

${ }^{49}$ Riset ini melibatkan 113 (dari 500 orang yang dihubungi) orang responden pekerja level eksekutif yang menghandle IT di perusahaannya, misal CIO, CTO, Digital Innovation Manager, berdasarkan data kontak mitra yang dimiliki Norwegian University of Science and Technology (NTNU).

${ }^{50}$ P. Mikalef et al., "The Human Side of Big Data: Understanding the Skills of the Data Scientist in Education and Industry," in 2018 IEEE Global Engineering Education Conference (EDUCON), 2018, 508.
} 


\section{Gambar 1.}

Perbandingan Kebutuhan Data Skills oleh Industri vs Kemampuan Institusi Pendidikan ${ }^{51}$

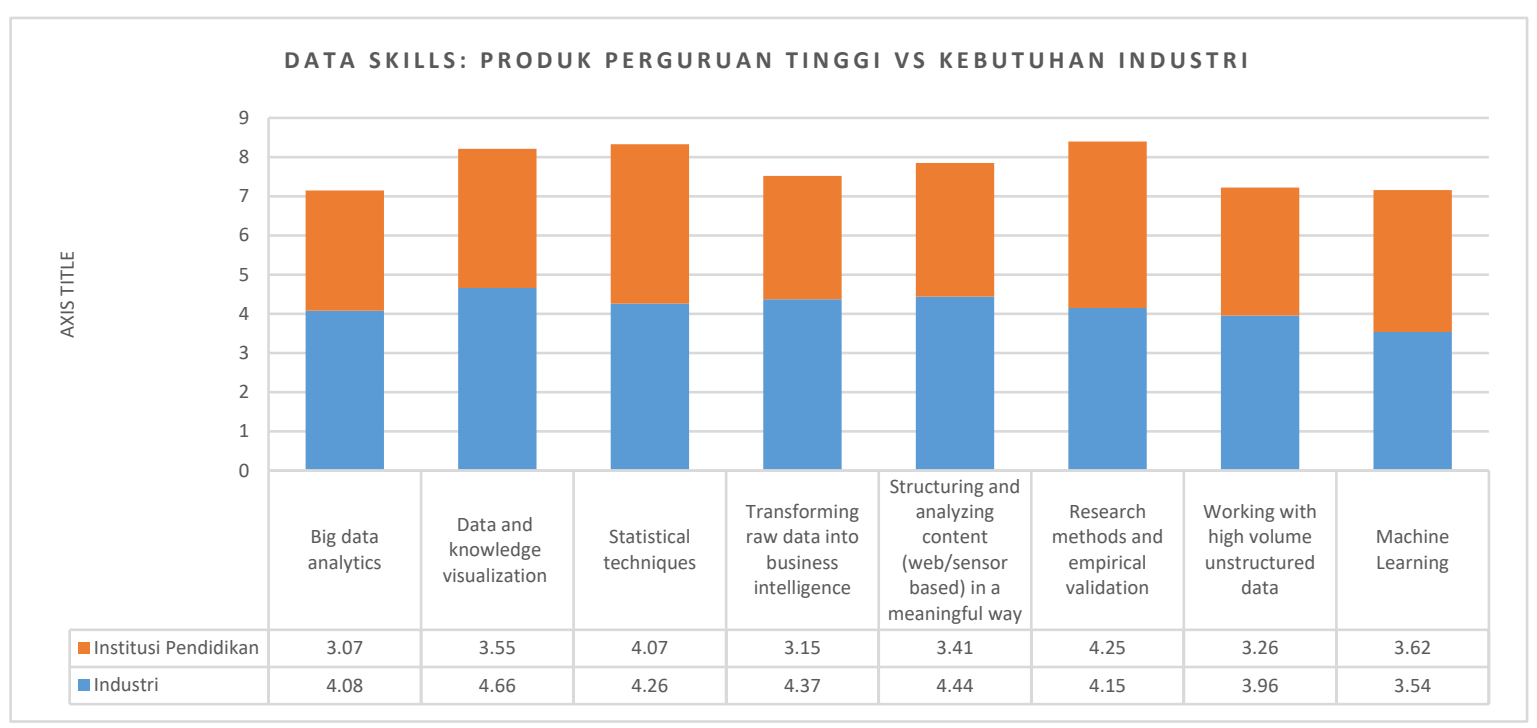

Dari riset Mikalef, dkk. nampak bahwa masih terjadi ketimpangan antara kebutuhan industri dengan kompetensi data skills lulusan oleh program studi informatika dan sejenisnya. Di sisi lain, keterampilan coding dan olah big data merupakan keterampilan yang cukup dibutuhkan di tengah tantangan revolusi data, termasuk untuk memperbanyak portal guna menguasai narasi moderat daring. Celah ini dapat dimasuki oleh lembaga-lembaga pendidikan non-formal yang cepat menangkap peluang untuk menyiapkan tenaga terampil dalam program pembelajaran non gelar untuk mengisi kebutuhan data scientist profesional di berbagai bidang --termasuk sektor media dan informasi-- meski tanpa gelar akademik.

Untuk menghasilkan software-enjin-robot yang dapat memproduksi konten moderat secara otomatis dengan bahasa natural dibutuhkan tenaga ahli yang menguasai bahasa pemrograman yang fleksibel untuk bekerja dalam data science. Di antara bahasa pemrograman yang populer digunakan oleh data scientist untuk mengolah big data adalah $\mathrm{R}$ dan Python.

$\mathrm{R}$, sebagaimana Python merupakan bahasa pemrograman yang sangat populer untuk keperluan data science. RStudio, aplikasi dengan interactive development environtment (IDE) untuk bekerja dengan bahasa pemrograman $\mathrm{R}$ memiliki beragam kelebihan karena di samping dapat mengolah dan mengeksplorasi data ia juga dapat digunakan untuk menganalisis dan meng-generate beragam chart $^{52}$ dengan library ggplot2. Package ini harus ditambahkan dalam RStudio atau R server untuk dapat membaca perintah ggplot sehingga user dapat memilih beragam grafik untuk menyajikan datanya. $R$ juga dapat digunakan untuk sekadar olah data statistik karena fungsinya yang sangat kompleks. Jika hanya

\footnotetext{
${ }^{51} \mathrm{lbid}$.

52 Jeanette M. Sperhac and Stephen M. Gallo, "VIDIA: A HUBzero Gateway for Data Analytics Education," Future Generation Computer Systems (2018): 6.
} 
untuk menganalisis data bivariat, multivariat, menghasilkan grafiknya, menganalisis populasi, regresi linier, hingga untuk keperluan coding sebuah portal data sicence terotomasi, ${ }^{53}$ ia sangat mumpuni.

\section{F. Hybrid Worldview Pesantren Moderat}

Untuk diterapkan di pesantren moderat yang menyelenggarakan tradisi bandongan, educative tradition tidak cocok karena menolak kepatuhan mutlak. Konsep Tan ini juga tidak memberikan ruang bagi kiai melanggengkan tradisi bandongan yang menempatkan kiai sebagai pusat pengetahuan (teacher-centered learning). Konsep ini juga tidak menawarkan gagasan untuk melakukan screening literasi santri dan siswa pesantren dari konten radikal dan belum mendorong pesantren berperan aktif menangkal radikalisme di jagat maya yang membutuhkan keahlian pemrograman guna mengembangkan software-enjin-robot untuk memproduksi wacana moderat, bukan hanya sekadar memberi informasi dan teknologi bagi santrinya.

Meskipun Miftahul Ulum memiliki SDM yang baik dalam bidang kepenulisan dan dapat melakukan kaderisasi kepenulisan populer pada santrinya, namun era 4.0 di sektor informasi, dibutuhkan skill coding untuk mengembangkan portal yang dapat melakukan kerja otomasi untuk menjaring data wacana moderat dan menyebar ulang gagasan moderat ini.

Untuk mengisi celah gagasan dan potensi lembaga ini, maka penulis mengusulkan hybrid worldview bagi Miftahul Ulum dan pesantren-pesantren moderat lain yang memiliki tradisi bandongan, memiliki madrasah diniyah dan lembaga pendidikan formal sekolah dan madrasah. Hybrid worldview merupakan cara pandang pengembangan pesantren moderat guna menangkal radikalisme sekaligus meresponnya. Cara pandang ini menempatkan kepatuhan mutlak dan takzim pada kiai sebagai tradisi adiluhung pesantren sekaligus sebagai distingsi yang harus dipertahankan.

Hybrid worldview sebagai wawasan pengembangan pesantren bertujuan pertama yang mendukung santri menjaga kepatuhan mutlak dan takzim pada kiai namun di kelas madrasah diniyah mampu menganalisis dan mengkontekstualisasikan materi dari kitab kuning dengan hasil riset terbaru dan realitas kekinian (competent worldview), melakukan analisis kritis-konstruktif atas teks, menghindarkan taklid dalam fikih, terbuka terhadap perubahan dan perbedaan, rasional dan otonom ${ }^{54}$ -sebagian konsep educative tradition diadopsi, sebagian lagi tidak-- sekaligus kedua melakukan screening buku yang mengandung konten radikal pada santri dan siswa, dan ketiga memiliki keahlian pemrograman dan keterampilan pengelolaan big data untuk menyebarkan gagasan moderat secara manual, maupun memproduksi software-enjin-robot yang secara otomatis melakukan produksi wacana moderat guna kontra narasi radikalisme daring.

Tentunya meski tidak semua pesantren dapat mengambil peran yang sama, namun Kementerian Agama hendaknya melakukan intervensi dengan menyusun roadmap pengembangan keterampilan

\footnotetext{
53 John Verzani, Using R for Introducory Statistics, Second Edition., The R Series (Boca Raton: Taylor \& Francis Group, 2014), vii-xiii.

${ }^{54}$ Tan, "Educative Tradition and Islamic School in Indonesia," 47-48.
} 
Mochammad Zaka Ardiansyah

santri dan siswa di beberapa pesantren yang diprioritaskan untuk didorong memiliki hybrid worldview, baik melalui pengembangan kurikulum anti-radikalisme, penyaringan konten radikal di buku teks sekolah dan madrasah, maupun menyiapkan pakar IT yang dilahirkan oleh rahim pesantren guna memperkuat wacana moderat.

Hybrid worldview membutuhkan komitmen pesantren untuk mengadaptasi kurikulum pesantren dengan realitas kekinian dengan maksud memberikan pemahaman moderat pada santri dan siswa lembaga pendidikan Islam sebagai "perangkat lunak" moderatisme di kancah daring ${ }^{55}$ dengan mencetak programmer software-enjin-robot.

Untuk mewujudkan santri yang memiliki hybrid worldview dijalankan dengan menjalankan dua misi, yakni misi pertama, memberikan pemahaman moderat pada santri dilakukan dengan mendorong pesantren melakukan pembelajaran hibrida dengan menjaga tradisi bandongan yang berpusat pada kiai sekaligus memberi kesempatan santri melakukan analisis induktif yang menempatkan santri sebagai agen aktif pengetahuan dengan dampingan ustaz menggunakan pembelajaran berpusat pada santri yang berbasis pada masalah keseharian sekaligus menyaring konten radikal masuk pesantren.

Dalam pembelajaran tradisional di pesantren, pertama santri belajar secara langsung dengan kiai menggunakan metode bandongan, di mana seluruh santri duduk melingkar atau di hadapan kiai untuk menyimak bacaan dan terjemahan teks kitab kuning, penjelasan dan terkadang kontekstualisasinya langsung dari kiai sambil menyalin apa yang diterjemahkan oleh kiai pada kitabnya masing-masing dan memberi catatan pinggir atas penjelasannya --yang pada umumnya menggunakan aksara pegon--, santri pun menyerap setiap informasi dari kiai secara pasif dengan menempatkan kiai sebagai pusat pembelajaran (teacher-centered learning). Dalam proses pembelajaran searah yang disertai hormat, kepatuhan, takzim, kepasrahan penuh semacam ini, santri berharap mendapatkan berkah dan kemanfaatan ilmu yang dipelajarinya dari kiai. Kepatuhan ini tak lain adalah dimensi integratif dari proses belajar dan pemerolehan ilmu dari kiai yang menjadi khas pesantren tradisional yang menjadi kan sosok kiai sebagai pusat kebudayaan, sehingga santri yang menerima setiap informasi dari kiai tanpa perdebatan. ${ }^{56}$ Kepatuhan penuh semacam ini terus terpelihara di pesantren tradisional moderat dan tidak relevan dengan educative tradition yang digagas Tan, karena kepatuhan pada kiai merupakan nilai yang dipegang teguh dan ditanamkan pada setiap santri sejak dini. ${ }^{57}$ Sementara diskusi dan analisis menurut penulis masih terbuka dan dibutuhkan di kelas madrasah diniyah yang diasuh ustaz.

Kedua, pembelajaran kritis di kelas madrasah diniyah. Pengetahuan satu arah kiai-santri dalam pembelajaran bandongan ini kemudian dianalisis di kelas-kelas madrasah diniyah dengan menempatkan

\footnotetext{
55 Thompson mengungkap betapa efektifnya sosial media untuk melakukan penyebaran paham radikal, paper yang dibuat pada 2011 ini menunjukkan pada kita betapa sosial media sudah lebih dari satu windu menjadi media penyebaran paham yang bertentangan dengan bangunan humanisme ini. Robin L. Thompson, "Radicalization and the Use of Social Media," Journal of Strategic Security 4, no. 4 (2011): 168-177; Erbschloe menyatakan bahwa ISIL memanfaatkan beragam bentuk kampanye melalui media sosial untuk menyebarkan propaganda dan ide-ide ekstrimisnya. Selengkapnya baca paparan Erbschloe Michael Erbschloe, Extremist Propaganda in Social Media: A Threat to Homeland Security (Boca Raton: CRC Press, 2018), 10.

${ }^{56}$ Bruinessen, "Pesantren Dan Kitab Kuning: Pemeliharaan Dan Kesinambungan Tradisi Pesantren," 74.

57 Ibid.
} 
santri sebagai pusat pengetahuan dengan student-centered learning.$^{58}$ Analisis di kelas madrasah diniyah dapat dilakukan dengan metode induktif dengan cara santri diajak mengidentifikasi masalah-masalah di sekitarnya atau ustaz menghadirkan masalah di kelas guna dianalisis, dievaluasi dan dirumuskan pemecahan masalahnya dengan desain pembelajaran problem-based learning ${ }^{59}$ Pembelajaran berbasis masalah sesungguhnya merupakan pembelajaran yang tidak hanya mengajak siswa untuk melakukan proses pembelajaran yang melatih keterampilan berpikir tingkat tinggi siswa melalui akuisisi informasi, namun juga melakukan analisis, mengevaluasi, mengambil keputusan dan mengembangkan solusi untuk memecahkan masalah. ${ }^{60}$

Belajar yang berangkat dari masalah tidak dimulai secara deduktif dengan mempelajari konsep, namun pemahaman dibangun secara induktif dari realitas. Alih-alih hanya menyajikan materi dan hasil analisis dari penulis kitab, ustaz madrasah diniyah menghadirkan masalah untuk dianalisis dengan materi yang disarikan mandiri santri terhadap teks kitab yang dilakukan sebelumnya di kamar sebelum sesi pembelajaran dimulai. Pembelajaran seperti ini berguna untuk menumbuhkan kepercayaan diri santri dan keterampilan berpikir ${ }^{61}$ tingkat tinggi pada santri.

Dalam pembelajaran berbasis masalah, santri pertama diarahkan untuk mengidentifikasi masalah di lapangan, dapat pula diidentifikasi dari kisah, film, gambar dan sebagainya, mereka kemudian diorganisir untuk belajar secara mandiri hingga kemudian dibimbing dan dipandu untuk melakukan investigasi secara mandiri atau berkelompok, mereka kemudian mengembangkan karya untuk dipamerkan, dan diakhiri dengan menganalisis dan mengevaluasi rangkaian kerja yang telah dilakukan. ${ }^{62}$

Gambar 2.

Diagram alur pembelajaran pesantren yang menerapkan Hybrid Worldview

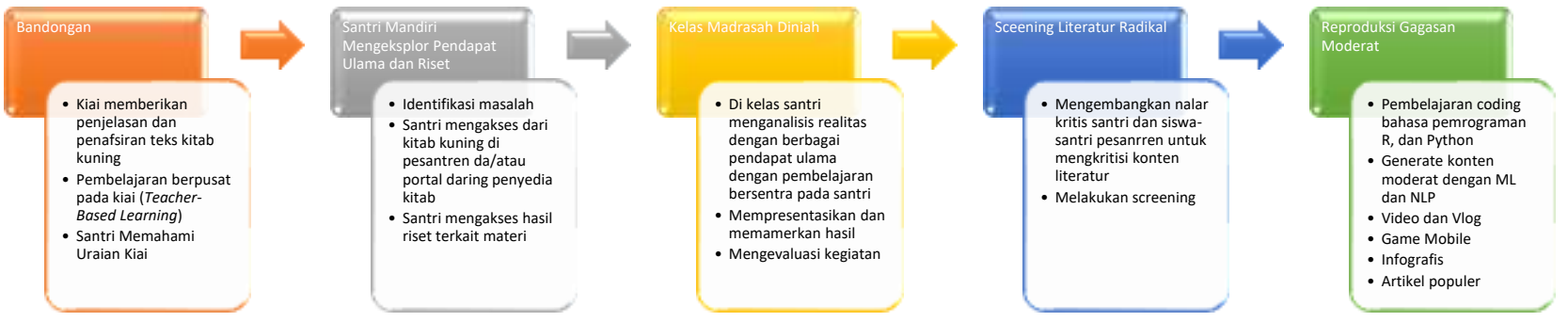

\footnotetext{
58 George M. Jacobs, Willy A. Renandya, and Michael Power, Simple, Powerful Strategies for Student Centered Learning (Switzerland: Springer, 2016), xiii-xiv.

${ }^{59}$ Santrock, Educational Psychology, 320.

${ }^{60}$ Gulistan A.M Saido, Saedah Siraj, and Abu Bakar Nordin, "Teaching Strategies Scale for Promoting Higher Order Thinking Skills among Students in Science" (presented at the ISER 5th International Conference, Singapore, 2015), 53-54.

${ }^{61}$ Santrock, Educational Psychology, 320.

62 Ibid.
} 
Misi kedua, menekuni literasi yang digunakan oleh lembaga pendidikan di bawah naungan holding-nya dan mendorong santri memiliki sense menyaring literasi radikal. Screening literatur dari konten radikal seyogyanya dilakukan pesantren, di samping dikembangkannya nalar kritis santri dan siswa pesantren untuk mengidentifikasi dan memberikan peringatan dini pada lembaga, kecuali pada siswa lembaga pendidikan anak usia dini, guru dan pesantrenlah yang dominan menyaring.

Temuan penulis dalam halaqah dan betapa dominannya literatur keislaman kanan di kalangan anak muda tidak dapat dilepaskan dari orientasi dagang toko buku yang tak sensitif ideologi, dengan kata lain toko-toko buku tersebut tunduk pada selera pasar tanpa berpihak pada langgengnya bangunan kemajemukan dan kebinekaan yang selama ini diperjuangkan negara. Untuk menetralisir skema radikal sebagai dampak bacaan radikal yang terlanjur ditelan santri dan siswa pesantren, lembaga dapat melakukan intervensi pendekatan asimilasi, yakni menginternalisasi pemahaman baru untuk memodifikasi skema yang dimiliki santri dan-siswa santri.

Sementara misi terakhir melakukan reproduksi gagasan moderat. Misi ini merupakan solusi futuristik untuk menangkal radikalisme melalui pemenangan kontestasi wacana moderat daring. Santri dan alumni pesantren sebagai kelompok cerdik-cendekia muslim tradisional moderat sangat tepat untuk digunakan sebagai agen penyeimbang narasi radikal daring melalui "peternakan" portal-portal cerdas penghasil wacana moderat daring. Alih-alih hanya diberikan bekal keterampilan memproduksi wacana, santri sangat potensial jika diberikan keterampilan pemrograman dan pengelolaan big data.

Misi ini menjadi keniscayaan, karena ke depan alumni lembaga pendidikan Islam tidak hanya dituntut tampil menyebarkan gagasannya melalui ceramah konvensional, namun aktif berkontribusi memperkokoh bangunan wacana dan pemikiran moderat melalui media daring dengan menciptakan software-enjin-robot --berbentuk portal-portal dengan kecerdasan buatan-- untuk menghasilmokan wacana moderat dalam beragam bentuk produk konten moderat dengan teknologi Machine Learning (ML) dan Natural Language Processing (NLP), konten pop-culture semacam video dan vlog, mobile game, infografis, artikel populer, film islamis populer dan novel.

Untuk konten moderat, mengingat tren pekerjaan di sektor informasi yang disuguhkan McKinsey semakin terotomasi, maka untuk menghasilkannya tak hanya membutuhkan keterampilan jurnalisme konvensional, namun juga membutuhkan keahlian coding guna membuat software-enjin-robot berupa portal artikel moderat dengan kecerdasan buatan yang dapat menyusun konten ramah-moderat dengan bahasa manusia secara otomatis. Portal-portal ini sebagai kekuatan penyeimbang wacana radikal sekaligus guna kontra narasi.

Jika portal-portal media, blog dan situs daring yang dikendalikan kelompok intoleran melakukan data mining konten situs dan percakapan media sosial dan mengolahnya menjadi konten radikal, propaganda, hoax dan kebencian secara otomatis sementara "kaum sarungan" belum memiliki sumber daya manusia untuk melakukan kontra narasi dengan metode yang sama, maka penulis memprediksi isu- 
isu yang berkembang secara daring akan dikuasai oleh narasi radikal karena tidak ada kekuatan yang mengimbanginya.

Untuk mewujudkan misi ketiga, pesantren dapat mulai mengagendakan untuk mengajarkan bahasa pemrograman $\mathrm{R}$ sejak dini. $\mathrm{R}$ cukup populer untuk dipakai mengembangkan machine learning guna melakukan beberapa tuas, pertama melakukan penambangan data (data mining atau juga kerap disebut data extraction ${ }^{63}$ ) dari artikel terbuka para ilmuwan muslim moderat di opini media daring yang dan akun media sosial pribadinya, kedua, mengorganisir dan ketiga, menganalisisnya, baik secara otomatis (data analytics) untuk menghasilkan insight yang lebih akurat menggunakan data processing tools, maupun oleh seorang data analis (proses data analysis) jika sangat dibutuhkan ${ }^{64}$ untuk selanjutnya diproses menggunakan NLP. Pengambilan, pengolahan dan penyajian konten tentu harus memenuhi etika publikasi media massa daring.

\section{G. Kesimpulan}

Dari deskripsi di atas, dapat disimpulkan bahwa pesantren Miftahul Ulum Jember dapat dijadikan sebagai role model yang menerapkan Hybrid Worldview, yakni cara pandang dan revolusi kurikulum pesantren moderat yang mendorong santri melestarikan tradisi kepatuhan pada kiai. Di sisi lain, cara pandang ini juga mendorong santri agar fokus mengembangkan nalar kritis, memiliki competent worldview, adaptif terhadap dinamika zaman dan menerima perbedaan, rasional dan otonom, selektif terhadap literatur siswa pesantren. Dengan wacana ini pula, santri dapat meiliki keahlian coding dengan bahasa pemrograman $\mathrm{R}$ dan pengelolaan big data bagi santri. Hal ini bertujuan untuk mempercepat pertumbuhan portal produsen wacana moderat untuk memenangkan perebutan wacana daring. Melalui artikel ini, ada beberapa hal yang perlu dijadikan refleksi, di antaranya: Pertama, di era digital, sangat penting bagi pesantren untuk memiliki hybrid worldview: sebuah cara pandang pengembangan pesantren moderat guna menangkal radikalisme sekaligus meresponnya. Cara pandang ini menempatkan kepatuhan mutlak dan takzim pada kiai sebagai tradisi adiluhung pesantren sekaligus sebagai distingsi yang harus dipertahankan. Kedua, pengembangan kurikulum pesantren menjadi misi penting yang perlu dikedepankan. Misi tersebut dilakukan agar pesantren memiliki wacana dan tradisi keilmuan yang berkembang dan berbasis pada moderatisme. Selanjutnya, pesantren mengimplementasikan strategi screening literatur radikal, dan strategi intervensi menggunakan akomodasi ala Piaget dalam pembelajaran. Sebagai bentuk aksi, pesantren perlu mengembangkan software-enjin-robot agar mereka dapat aktif memperbanyak portal untuk memproduksi wacana moderat daring dan mengimbangi narasi radikal.

\footnotetext{
${ }^{63}$ Markus Moessner et al., "Analyzing Big Data in Social Media: Text and Network Analyses of an Eating Disorder Forum” 51, no. 7 (2018): 4-5.

${ }^{64}$ M. Prakash, G. Padmapriy, and M. V. Kumar, "A Review on Machine Learning Big Data Using R," in 2018 Second International Conference on Inventive Communication and Computational Technologies (ICICCT), 2018, 1874.
} 


\section{H. Referensi}

Auda, Jasser. Maqasid Al-Syari'ah as Philosophy of Islamic Law: A Systems Approach. London: The International Institute of Islamic Thought, 2007.

Azra, Azyumardi, and Dina Afrianty. "Pesantren and Madrasa: Modernization of Indonesian Muslim Society." Boston: Boston University, 2005.

Badrus. “Wawancara Profil Pesantren Miftahul Ulum Kalisat Jember," March 10, 2016.

- - - "Wawancara Tradisi Belajar Di Sekolah Dan Madrasah Pesantren Miftahul Ulum Kalisat Jember," Desember 2018.

Baharun, Hasan dan Awwaliyah, Robiatul. " Pendidikan Multikultural dalam Menanggulangi Narasi Islamisme di Indonesia". Jurnal Pendidikan Agama Islam (Journal of Islamic Education Studies), Vol. 5, No. 2 (2017).

Baisuki, Asror. "Penanaman Karakter Moderat di Ma'had Aly Situbondo". Edukasi: Jurnal Penelitian Pendidikan Agama dan Keagamaan, Vol. 15 No. 3 (Desember 2017).

Baytiyeh, Hoda. “Have Globalisation's Influences on Education Contributed to The Recent Rise of Islamic Extremism?" Globalisation., Societies and Education (2018).

Beritagar.id. "Tentang Kami - Merawat Indonesia." Accessed November 27, 2018. https://beritagar.id/tentang-kami.

Bruinessen, Martin van. "Pesantren Dan Kitab Kuning: Pemeliharaan Dan Kesinambungan Tradisi Pesantren." Jurnal Ulumul Qur'an 3, no. 4 (1992).

Convey Indonesia. "Survei PPIM 2018: Ada 3 Hal Terkait Intoleransi Dan Radikalisme Di Kalangan Guru - Convey Indonesia," n.d. Accessed December 6, 2018. https://conveyindonesia.com/surveippim-2018-ada-3-hal-terkait-intoleransi-dan-radikalisme-di-kalangan-guru/.

Darajat, Zakiya. "Muhammadiyah dan NU; Penjaga Moderatisme Islam di Indonesia". Hayula: Indonesian Journal of Multidisciplinary Islamic Studies, Vol. 1, No. 1 (Januari 2017).

Dhofier, Zamakhsyari. "The Pesantren Tradition: A Study of the Role of the Kyai in the Maintenance of the Traditional Ideology of Islam in Java." Disertasi, Australia National University, 1980.

Ecomonist, The. Automation Readiness Index: 2017, n.d. http://www.automationreadiness.eiu.com/static/download/Report.xlsm.

- - - "The Automation Readiness Index 2018." Accessed December 6, 2018. http://automationreadiness.eiu.com.

-- - The Automation Readiness Index: Who Is Ready for The Coming Wave of Automation? London: The Economist Intelligence Unit, 2018.

Erbschloe, Michael. Extremist Propaganda in Social Media: A Threat to Homeland Security. Boca Raton: CRC Press, 2018.

Farida, Umma. "Radikalisme, Moderatisme Dan Liberalisme Pesantren: Melacak Pemikiran Dan Gerakan Keagamaan Pesantren Di Era Globalisasi." Edukasia 10, no. 1 (2015). 
Hasan, Noorhaidi. "The Failure of the Wahhabi Campaign Transnational Islam and the Salafi Madrasa in Post-9/11 Indonesia." South East Asia Research 18, no. 4 (n.d.).

Hilmy, Masdar. "Radikalisme Agama dan Politik Demokrasi di Indonesia Pasca-Orde Baru". Miqot: Jurnal Ilmu-ilmu Keislaman, Vol. 39, No. 2 (2015).

Ikhwan, Munirul. "Produksi Wacana Islam(Is) Di Indonesia: Revitalisasi Islam Publik Dan Politik Muslim." In Literatur Keislaman Generasi Milenial: Transmisi, Apropriasi, Dan Kontestasi, edited by Noorhaidi Hasan. Yogyakarta: Pascasarjana UIN Sunan Kalijaga Press, 2018.

Jacobs, George M., Willy A. Renandya, and Michael Power. Simple, Powerful Strategies for Student Centered Learning. Switzerland: Springer, 2016.

Lukens-Bull, Roland A. "Teaching Morality: Javanese Islamic Education in A Globalizing Era." Journal of Arabic and Islamic Studies 3 (2000).

Lukens-Bull, Ronald. "The Tradition of Pluralism, Accomodation, and Anti Radicalism in the Pesantren Community." Journal of Indonesian Islam 2, no. 1 (June 2008).

Manyka, James, Michael Chui, Mehdi Miremadi, Jacques Bughin, Katy George, Paul Willmott, and Martin Dewhurst. A Future That Works: Automation. Employment, and Productivity. McKinsey Global Institute, 2017.

Masduqi, Irwan. "Deradikalisasi Pendidikan Islam Berbasis Khazanah Pesantren." Jurnal Pendidikan Islam 2, no. 1 (June 2013).

McLuhan, Marshall, and Quentin Fiore. War and Peace in the Global Village. New York: Bantam Books, 1968.

Mikalef, P., M. N. Giannakos, I. O. Pappas, and J. Krogstie. "The Human Side of Big Data: Understanding the Skills of the Data Scientist in Education and Industry." In 2018 IEEE Global Engineering Education Conference (EDUCON), 503-512, 2018.

Moessner, Markus, Johannes Feldhege, Markus Wolf, and Stephanie Bauer. "Analyzing Big Data in Social Media: Text and Network Analyses of an Eating Disorder Forum" 51, no. 7 (2018).

Moulton, Jeanne. Madrasah Education: What Creative Associates Has Learned. Washington DC: Creative Associates International, 2008.

Noorhayati, S. Mahmudah. "Redesain Paradigma Pendidikan Islam Toleran dan Pluralis di Pondok Pesantren (Studi Konstruktivisme Sikap Kiai dan Sistem Nilai di Pondok Pesantren Nurul Jadid, Paiton, Probolinggo)". Jurnal Pendidikan Agama Islam (Journal of Islamic Education Studies), Vol. 5, No. 1 (2017).

PPIM. "Survei PPIM 2018: Menyibak Intoleransi Dan Radikalisme Guru." PPIM / Pusat Pengkajian Islam Dan Masyarakat. Accessed December 6, 2018. https://ppim.uinjkt.ac.id/category/2/post/surveippim-2018:-menyibak-intoleransi-dan-radikalisme-guru.

Prakash, M., G. Padmapriy, and M. V. Kumar. "A Review on Machine Learning Big Data Using R." In 2018 Second International Conference on Inventive Communication and Computational Technologies (ICICCT), 1873-1877, 2018.

Republika. "BNPT Curigai 19 Pondok Pesantren Dukung Terorisme." Republika Online. Last modified February 2, 2016. Accessed September 10, 2016. 
http://www.republika.co.id/berita/nasional/umum/16/02/02/o1xafr365-bnpt-curigai-19pondok-pesantren-dukung-terorisme.

Saido, Gulistan A.M, Saedah Siraj, and Abu Bakar Nordin. "Teaching Strategies Scale for Promoting Higher Order Thinking Skills among Students in Science." Singapore, 2015.

Santrock, John W. Child Development: An Introduction. Thirteenth Edition. New York: McGraw-Hill, 2011.

---. Educational Psychology. 6th ed. New York: McGraw-Hill, 2011.

Siradj, Said Aqil. Tasawuf Sebagai Kritik Sosial: Mengedepankan Islam Sebagai Inspirasi Bukan Aspirasi. Bandung: Mizan, 2006.

Slavin, Robert E. Educational Psychology: Theory and Practice. 8th ed. Boston: Pearson Education, 2006.

Sperhac, Jeanette M., and Stephen M. Gallo. "VIDIA: A HUBzero Gateway for Data Analytics Education." Future Generation Computer Systems (2018).

Syauqi, Itqon. "Wawancara Pernyataan Kesediaan Untuk Dipublikasikan,” Desember 2018.

Tan, Charlene. "Educative Tradition and Islamic School in Indonesia." Journal of Arabic and Islamic Studies, no. 14 (2014).

---. Islamic Education and Indoctrination: The Case in Indonesia. New York: Routledge, 2011.

Thompson, Robin L. "Radicalization and the Use of Social Media." Journal of Strategic Security 4, no. 4 (2011).

Verzani, John. Using R for Introducory Statistics. Second Edition. The R Series. Boca Raton: Taylor \& Francis Group, 2014.

“Pangkalan Data Pondok Pesantren." Accessed December 7, 2018. http://pbsb.ditpdpontren.kemenag.go.id/pdpp/grafik.

Transkrip Halaqoh Pesantren Sebagai Pusat Komunitas Anti Radikalisme. Amr. Musala Ponpes Miftahul Ulum Taman Baru, 2016. 